\title{
Phalaenopsis wilsonii (Orchidaceae: Epidendroideae: Vandeae), a new record for India
}

\author{
Kamba J. \& C.R. Deb* \\ Department of Botany, Nagaland University, Lumami, Nagaland - 798 627, India \\ `E-mails: debchitta@rediffmail.com, debchitta@gmail.com
}

\begin{abstract}
Phalaenopsis wilsonii Rolfe (Orchidaceae) is reported as a new distributional record for the orchid flora of India from Nagaland. Detailed colour photographs are provided for easy identification. With this addition the genus is represented by six species in Nagaland, India.
\end{abstract}

Keywords: Nagaland, New record, Orchid flora, Taxonomy.

\section{Introduction}

The genus Phalaenopsis Blume (Orchidaceae) was established in 1825, with the generic name being derived from the Greek words "phalaina" (moth) and "opsis" (appearance), referring to moth-like flower. The genus comprises approximately 97 species distributed worldwide (Govaerts et al., 2021). Christenson (2001), divided the genus into five subgenera: Proboscidioides (Rolfe) Christenson, Aphyllae (H.R.Sweet) Christenson, Parishianae (H.R.Sweet) Christenson, Polychilos (Breda) Christenson and Phalaenopsis Blume. The subgenera Aphyllae, Parishianae and Proboscidioides are distributed in southern China and India, extending to northern Vietnam, Myanmar and Thailand while the subgenus Polychilos has a few species distributed as far west as northeastern India, but primarily is centred in Indonesia and the Philippines (Christenson, 2001). Species of Phalaenopsis are found throughout tropical Asia and the larger islands of the Pacific Ocean and range from Sri Lanka and southern India in the west, to

Received: 26.02.2021; Revised \& Accepted: 29.09.2021

Published Online: 16.10.2021
Papua New Guinea in the east, to the Yunnan province (southern China) and Taiwan in the north, and to northern Australia in the south. The genus is represented by 15 species in India (Singh et al., 2019).

During a recent field survey to document the vandaceous orchid resources of Nagaland, the authors encountered a seemingly new orchid species in vegetative state (Fig. 1a) and brought it under cultivation at the Orchidarium of the Department of Botany, Nagaland University, during 2018. The specimen flowered during AprilJune 2021 (Fig. 1b), and was identified as Phalaenopsis wilsonii Rolfe, until now considered restricted to China and might have an extended distribution in northern Vietnam. The present report forms a new distributional record for India, and the genus has now six species in Nagaland, namely, P. deliciosa Rchb.f., P. difformis (Wall. ex Lindl.) Kocyan \& Schuit., P. taenialis (Lindl.) Christenson \& Pradhan, P. hygrochila J.M.H. Shaw, P. yingjiangesis (Z.H.Tsi) Kocyan \& Schuit. and $P$. wilsonii Rolfe (Deb \& Imchen, 2008; Deb \& Jakha, 2019). A detailed description along with colour photographs are provided for easy identification.

\section{Materials and Methods}

Living specimens of Phalaenopsis wilsonii were brought into cultivation at the Orchidarium of the Department of Botany, Nagaland University, in 2018. Identity of the specimen was confirmed on flowering, in consultation with the protologue and other relevant literature (Rolfe, 1909; Christenson, 
2001; Chen et al., 2009) and the type specimens housed at $\mathrm{K}$ and $\mathrm{BM}$.

\section{Taxonomic Treatment}

Phalaenopsis wilsonii Rolfe, Bull. Misc. Inform. Kew 1909: 65. 1909. Polychilos wilsonii (Rolfe) Shim, Malayan Nat. J. 36: 27. 1982. Kingidium wilsonii (Rolfe) O.Gruss \& Roellke, Orchidee (Hamburg) 47: 149. 1996. Doritis wilsonii (Rolfe) T.Yukawa \& K.Kita, Acta Phytotax. Geobot. 56(2): 157. 2005. Type: CHINA, western China, without precise locality, E.H. Wilson 4576 (syn K [K000891370, K000891371 digital images!]; BM [BM000534956 digital image!]).

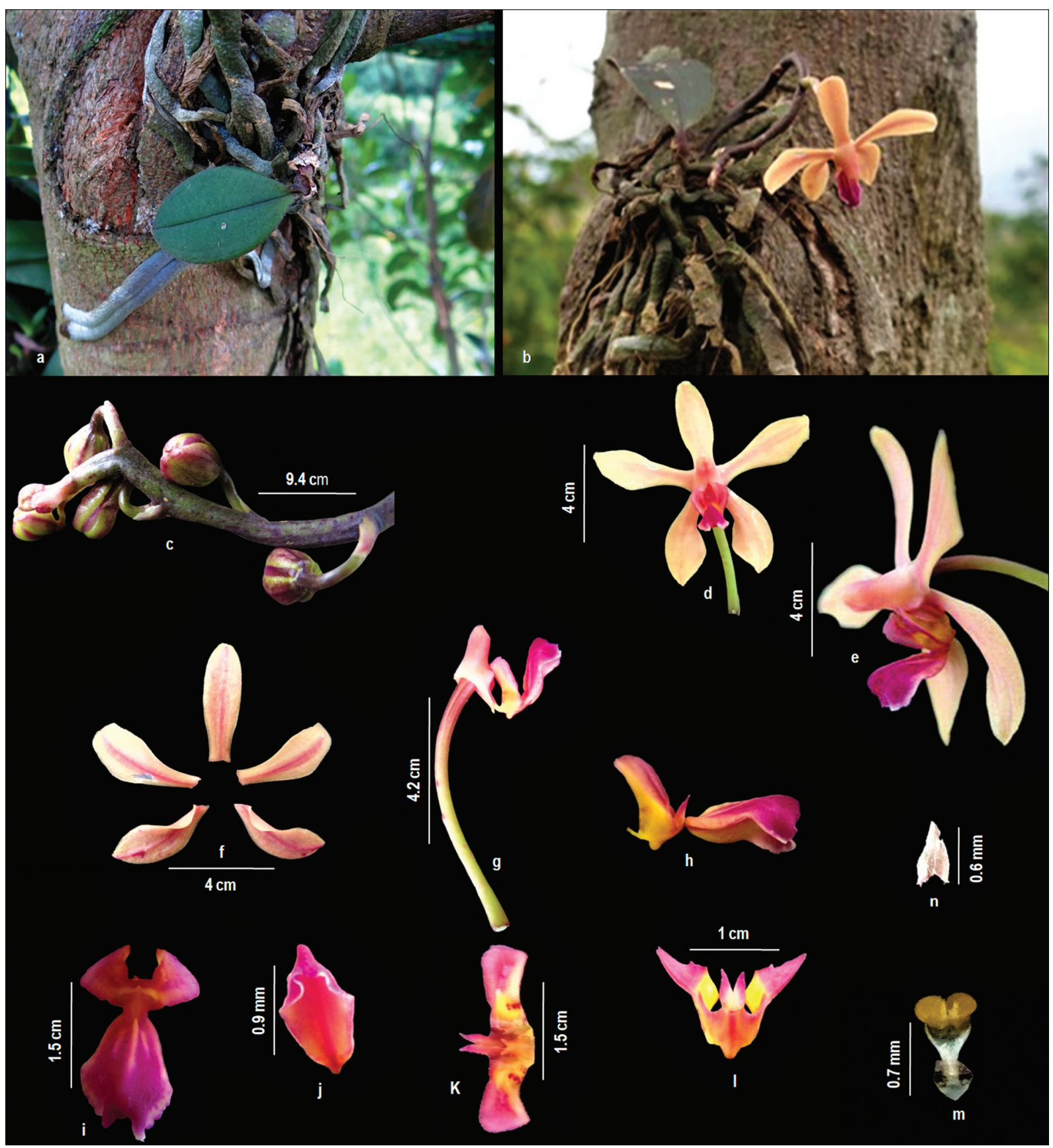

Fig. 1. Phalaenopsis wilsonii Rolfe: a. Plant in vegetative state; b. Plant in flowering; c. Inflorescence; d. Single flower; e. Flower-side view; f. Ventral sepals and petals; g. Column with pedicelled ovary and 3-lobed lip; h. Lip-side view; i. Lip-top view; j. Lip bottom view; k. Lip callosities; I. Spur beneath posterior callus; m. Pollinia; n. Bract (from J. Kamba 102; photos by J. Kamba). 
Phalaenopsis minor F.Y.Liu, Acta Bot. Yunnan. 10: 119. 1988.

Phalaenopsis wilsonii Rolfe f. azurea Z.J.Liu \& Z.Z.Ru, Orchidee (Hamburg) 57: 318. 2006. Fig. 1

Plants c. $4 \mathrm{~cm}$ long. Roots well developed, densely verrucose, elongate, fasciculate, fleshy, flattened, greenish. Stem $0.8-1 \mathrm{~cm}$ long. Leaves usually 1 or 2, sometimes leafless, 6-7 × 2.2-2.4 cm, purple green, oblong-elliptic, apex acute. Flower stalk 7$10 \mathrm{~cm}$ long, arcuate, zigzag. Bracts ovate-triangular, apex acute, c. $6 \times 4 \mathrm{~mm}$, membranous. Flowers few, widely opened, 4-5 cm broad, widely spaced. Sepals, petals orange-peach, colour prominent at base, mauve, lip magenta color, column white or pinkish. Dorsal sepal oblong-elliptic, c. $20 \times 6 \mathrm{~mm}$, acute or sub-obtuse at apex. Lateral sepals oblique, c. $16 \times 7 \mathrm{~mm}$, acute at apex. Petals spatulate, elliptic or oblong-ovate, c. $18 \times 8 \mathrm{~mm}$, obtuse at apex. Clawed at lip base, lip three-lobed; lateral lobes erect, sickle-shaped, 5-8 $\mathrm{mm}$, adaxially incisedtipped keel; mid-lobe obcordate when spread, c. 9 $\times 5 \mathrm{~mm}$, fleshy hump, convex, notched at apex, medium keel raised at base. Column erect, $6-8 \mathrm{~mm}$, adaxial stigmatic cavity. Pedicellate ovary. Anther cap shortly beaked, white-purplish on dorsal side. Pollinia four, in two unequal pairs. Capsules 2-3 $\times$ $0.5-0.7 \mathrm{~cm}$, cylindric.

Flowering \& fruiting: Flowering from April to May; fruiting from May to July.

Habitat: Epiphytic on mossy tree trunks. Only two individuals were spotted growing together.

Distribution: China, now in India. Likely to have an extended distribution in northern Vietnam (Christenson, 2001).

Specimen examined: INDIA, Nagaland, Zunhebhoto district, Kithsakita, N 26 621922 E 94322 1422 , 1529 m, 01.07.2017, J. Kamba 102 (Nagaland University Herbarium).

\section{Acknowledgements}

The people of Kithsakita, Zunheboto district, Nagaland, supported the field work. The University Grants Commission (UGC), Government of India, New Delhi provided a BSR Research Fellowship for the Ph.D. programme to KJ. Facilities used in the Department of Biotechnology, Ministry of Science and Technology, New Delhi, India sponsored 'Institutional Biotech Hub', UGCSAP(DRS-III) and DST-FIST programmes, help received from Dr. Hubert Kurzweil, Orchid Specialist (Singapore Botanic Garden) and Paul Ormerod (Cairns, Australia) for confirming the correct identity of the taxon.

\section{Literature Cited}

CHRISTENSON E.A. 2001. Phalaenopsis. Timber Press, Portland.

DEB C.R. \& T. IMCHEN 2008. Orchid diversity of Nagaland. SciChem Publishing House, Udaipur.

DEB C.R. \& H.Y. JAKHA 2019. Orchid diversity in three districts [Kiphire, Tuensang and Zunheboto] of Nagaland, India. Pleione 13: 203-215.

GOVAERTS R., BERNET P., KRATOCHVIL K., GERLACH G., CARR G., ALRICH P., PRIDGEON A.M., PFAHL J., CAMPACCI M.A., HOLLAND D., BAPTISTA TIGGES H., SHAW J., CRIBB P., GEORGE A., KREUZ K. \& J. WOOD 2021. World Checklist of selected plant families. Facilitated by the Royal Botanic Gardens, Kew. Available at: http:// wcsp.science.kew.org (Accessed on 26.02.2021).

SINGH S.K., AGRAWALA D.K., JALAL J.S., DASH S.S., MAO A.A. \& P. SINGH 2019. Orchids of India-a pictorial guide. Botanical Survey of India, Kolkata.

CHEN X., LIU Z., ZHU G., LAKNG K.-Y., JI Z., LUO Y.-B., JIN X., CRIBB P.J., WOOD J.J., GALE S.W., ORMEROD P., VERMEULEN J., WOOD H.P., CLAYTON D. \& A. BELL 2009. Orchidaceae. In: WU Z., RAVEN P.H. \& D. HONG (eds.), Flora of China. Volume 25. Orchidaceae. Missouri Botanical Garden Press, Missouri.

ROLFE R.A. 1909. New orchids: Decade 33. Bulletin of Miscellaneous Information, Royal Gardens, Kew 1909: 65. 